\title{
As práticas imitativas musicais na Missa em Si menor de Bach
}

KATIA KATO

FACULDADE NAZARENA DO BRASIL (pkjusti@uol.com.br)

\begin{abstract}
X processo de produção artística a música ocupa um lugar de destaque como um dos principais meios de imitação. As práticas imitativas que utilizavam a música como ferramenta para imitar, suscitar e representar afetos, preconizada desde os antigos, chegam integralmente ao século XVIII e são claramente observadas nas obras dos compositores alemães ligados à doutrina composicional da Musica Poetica e, sobretudo, na obra de Johann Sebastian Bach. Porém, as práticas imitativas da paródia, contrafactum, emulação, ainda que possam nos remeter a práticas imitativas semelhantes, se diferenciam de acordo com sua aplicação em diferentes áreas, seja no campo da literatura, da oratória ou ainda na composição musical, sendo inicialmente utilizadas como ferramentas pedagógicas por retóricos, literatos e compositores. Através dos tempos, dos usos e costumes, assumem conotações variadas que se confundiam ora com a homenagem, no caso da emulação e da imitação, ora com o plágio ou "roubo", como da paródia.

Assim, com o intuito de tentarmos desvendar quais procedimentos imitativos retórico-musicais J.S. Bach fazia na reutilização de suas composições, sobretudo no que concerne às obras reutilizadas na Missa em Si menor, BWV 232, procuramos definir cada termo, realizando um apanhado histórico de seu surgimento, bem como em quais condições foram utilizados.
\end{abstract}

\section{A imitação musical - Emulação, Contrafactum e Paródia}

A prática da imitação musical já era uma constante nas composições anteriores ao século XVIII, porém, foi em 1739 
que o teórico Johann Mattheson, em seu tratado Der vollkommene Capellmeister, descreve e categoriza a imitação musical. Diz ele:

Exatamente como numa discussão, na qual cada fala é respondida apenas com sim ou não, e na qual nenhum exame é efetuado, nenhuma asserção é apresentada, nenhum contra-argumento é discernido, nenhuma pequena amigável contestação apresentada, assim também, [na composição] quando absolutamente nenhum esforço for feito para imitar ou para destacar, logo se tornará em algo sonolento e causará um mau deleite; assim também ocorrerá em cada harmonia, mesmo que ela seja constituída de somente duas vozes, ainda certamente exigirá tais explicações, objeções, analogias e argumentos nos sons [música], que não temos como atender através de nenhum meio melhor, a não ser pela imitação, também conhecida por imitatio ou aemulatio vocum. Esta imitação tem três diferentes sentidos na música. No primeiro encontramos a oportunidade de imitar todos os tipos de coisas naturais e afecções de ânimo, que é, indubitavelmente, o maior auxílio para a inventio, como já discutimos acima. Desde que não se configure em nenhum roubo de forma musical, o segundo sentido refere-se aos problemas que temos na imitação de uma ou outra obra de mestre ou compositor. 0 terceiro sentido refere-se ao que pode ser observado através da imitação de agradáveis competições, nas quais diferentes vozes se guiam com toda a liberdade sobre conhecidas regras formais, motivos, passagens e frases $^{1}(\S .3-4,331)$.

1 Tradução de Paulo Justi. §.3. Denn, gleichwie eine Unterredung, da zu allen Vorträgen blosserdings Ja oder Nein gesaget, und keine Untersuchung vorgenommen, keine Behauptung angebracht, keine Gegenrede verspüret, kein kleiner freundlicher Streit erregt, ja, gar keine Mühe genommen wird, es einander nach oder auch zuvorzuthun, gar bald schläfrig macht, und schlechte Freude erwecket: also erfordert auch eine iede Harmonie, wenn sie gleich nur aus zwo Stimmen bestünde, eben solche Erörterung, Einwürffe, Beisprüche und Lutgefechte in den klängen, die man durch kein bessers Mittel, als durch die so genannte Nachahmung, welche mit ihren Kunstworte, Imitatio, vel potius Aemulatio vocum heisset, vorstellig machen kan. 
Mattheson trata dos aspectos técnicos relativos à composição e relata o uso do termo imitatio de três maneiras distintas: como imitação de coisas naturais e afecções de ânimo; como imitação de obra de outro mestre ou compositor e como imitação de vozes, sendo que esta última variante indica uma forma livre de imitação. Neste contexto de imitação proposto por Mattheson, através da cópia da obra de mestres ou modelos previamente compostos, podemos incluir os conceitos de paródia e emulação.

Para H. Brown (1982, p. 8-10), assim como os poetas e oradores, também os compositores aprenderam sua arte imitando os grandes mestres, moldando novas peças diretamente nos antigos. Ele argumenta que entre os séculos XV e XVII a ideia de criação de um trabalho musical totalmente novo, baseado em modelos pré-existentes, cresce a partir da respeitável tradição retórica da imitatio, elaborada particularmente pelos humanistas.

Weinbrot (1985, p. 121) esclarece que a prática da imitação marca a divisão entre a concepção artística do início e do final do século XVII, sendo que o ensino da imitação era um dispositivo essencial para a transmissão da pedagogia e literatura. Uma outra forma especialmente relevante do emprego da imitação na educação foi na tradução de textos em latim em solo inglês. João Adolfo Hansen, em seu artigo

§.4. Diese Nachahmung nun hat in der Music dreierley zu bedeuten. Denn erstlich finden wir Gelegenheit, dergleichen Uibung mit allerhand natürlichen Dingen und Gemüths-Neigungen anzustellen, worin schier das grösseste Hülfsmittel der Erfindung bestehet, wie an seinem Orte gesaget worden ist. Fürs andre wird diejenige Bemühung verstanden, so man sich gibt, dieses oder jenen Meisters und TonKünstlers Arbeit nachzumachen: welches eine gantz gute Sache ist, so lange kein förmlicher Musicalischer Raub dabey mit unterläufft. Drittens bemercket man durch die Nachahmung denjenigen angenehmen Wettstreit, welchen verschiedene Stimmen über gewisse Förmelgen, Gänge oder kurtze Sätze mit aller Freiheit unter einander führen. 
Imitação na representação seiscentista corrobora esta informação explicando que:

(...) nas práticas de representação italianas e ibéricas do século XVII, hoje unificadas como "Barroco", a autenticidade das obras era decorrência da imitação: nelas, os termos imitação e autenticidade não se excluíam como hoje; ao contrário, implicavam-se mutuamente. (...) Assim, nas preceptivas retóricas do século XVII, é rotineira a distinção entre piratear, imitar e emular. (...) Pressupõe-se, então, que o conhecimento e a aplicação regrada das distinções entre piratear, imitar e emular são fundamentais para obter a fama gloriosa de "emulador", como diz Sforza Pallavicino em seu Arte dello Stile Insegnativo, de 1644. (...) Desta maneira, a imitação louvável é especificada como emulação. Basicamente, a emulação visa produzir, por outros modos e por outros meios, um prazer semelhante ou superior ao da obra imitada. (...) Como imitação produzida pelo intelecto e pela arte, a emulação é uma imitação proporcionada. Pela emulação, a obra deve superar o imitado, tornando-se autoridade para novas emulações.

Emanuele Tesauro 2, no Capítulo III de seu Il

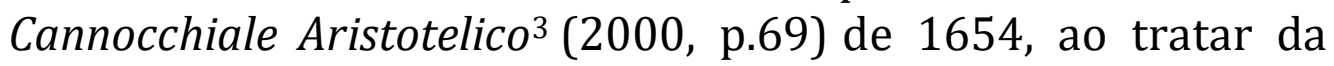
Agudezas Humanas, define a imitação como sendo o exercício mais eficaz e engenhoso de todas as agudezas humanas. Ele afirma:

Essa [a imitação] foi a antiga mestra de todos os homens, aos quais a Natureza parece ter sido muito relutante em querer que com muito esforço um homem seja discípulo de outro, quando para os animais ela mesma é mestra. 0 falar, o

2 Emanuele Tesauro (1592-1675) foi um dos mais importantes teóricos literários do período barraco na Itália. Em sua principal obra, Il Cannocchiale Aristotelico de 1645, desenvolvendo ideias esboçadas na poética renascentista e embasado na Retórica e Poética de Aristóteles, constrói uma vasta teoria sobre a metáfora e o conceitismo (Oxford Companion to Italian Literature, disponível em: http://www.answers.com/topic/emanuele-tesauro, Acessado em: 02. Jan. 2012).

${ }^{3}$ Agradeço à Profa. Dra. Monica Lucas pela tradução do texto. 
caminhar, o nadar, o cantar, o escrever ensinam-se por meio de simples imitação. As virtudes e os costumes civis são impressos na cera da alma tenra com a simples imitação dos pais e nutridores. Finalmente as artes todas, tanto as mecânicas quanto as liberais, são aprendidas a partir dos exemplos de ótimos artífices; e estes as aprenderam (tão injusta foi a Natureza) pela imitação dos animais. De modo que a imitação pode ser chamada mestra dos mestres. Essa, aliás, foi a primeira mestra da poesia cuja alma consiste no imitar (...). Portanto eu chamo imitação uma sagacidade com a qual sendo proposta para ti uma metáfora ou outra flor do engenho humano, tu atentamente examinas as suas raízes e transplantando-as em diferentes categorias, como em solo cultivado e fecundo, propagas outras flores da mesma espécie, mas não os mesmos indivíduos.

Porém, mesmo antes de Mattheson descrever e categorizar a imitação na música, o procedimento imitativo já havia sido tratado por exemplo por Isócrates (436-338 a.C.), retórico ateniense, que insistia em seus ensinamentos que a imitação deveria ser "grande, bela e humana", considerando-a como edificante tanto moral, como artisticamente. Dionísio de Halicarnasso (I a.C.-?), que ensinou em Roma antes do ano 30 a.C., em seu tratado Peri Mimeseos (Sobre a Imitação), define a mimesis como "uma atividade de se fazer um modelo de exemplo por meio de observação". A ela poderia ser combinada a "emulação" (zelos), ou seja, "uma atividade da alma, quando movida pela admiração do que parece ser belo" (SLOANE, 2001, p. 381-383). Nota-se assim que, tanto Isócrates quanto Dionísio de Halicarnasso, começam a preocupar-se em tornar a beleza e a edificação moral como itens a serem observados, imitados e emulados no discurso.

Assim, a beleza e a edificação moral se tornam partes do discurso, passando a ser imitados e emulados também na prática imitativa musical. Brown (1982, pp.8-10) explica que a prática de utilizar obras de grandes mestres como modelo e guia para estudantes pode bem ter sido a base para um princípio de pedagogia musical no século XVI. Entretanto, afirma que o princípio da imitação era bem conhecido em outros tipos de atividades intelectuais e artísticas durante o 
período, porém, acredita que nenhum teórico musical do século $\mathrm{XV}$, ou mais tarde no século XVI tenha discutido esta técnica detalhadamente. Prova disto é que a maior parte dos tratados em música da Idade Média e do início da Renascença inicia igualmente com técnicas básicas necessárias para o entendimento, execução musical e vários aspectos da arte da composição musical, porém, sem apresentar nenhuma discussão teórica sobre a prática imitativa ou da emulação. Outra maneira de emulação aparece nos manuscritos de música secular do século $\mathrm{XV}$, que por sua vez era claramente não pedagógica, uma vez que envolvia um compositor maduro que basearia uma nova composição em uma antiga composição de outro compositor maduro. Na verdade, os dois impulsos, imitação e emulação, são, sem dúvida, proximamente revelados, mas nota-se que a emulação utilizada com o intuito de homenagem era nitidamente uma técnica comum entre os compositores de canção do tardio século XV. O modo particular 200 como os compositores se imitavam foi noticiado em instâncias isoladas, mas nunca foram analisados conjuntamente e, tampouco, vistos como parte de uma técnica padrão do período.

A emulação, como um tipo de imitação ligada à moral, já ocorrera em Aristóteles, na Retórica ${ }^{4}$ :

A emulação consiste num certo mal estar ocasionado pela presença manifesta de bens honoríficos e que se podem obter em disputa com quem é nosso igual por natureza, não porque tais bens pertençam a outrem, mas porque também não nos pertencem (razão pela qual a emulação é uma coisa boa e própria de pessoas de bem (...) (1388 b).

Aristóteles define a emulação como uma espécie de inveja positiva, isto é, a imitação pela posse de bens. Para ele, emular é admirar (Ret. 1385a). Porém ele não se limita a tratar da emulação apenas no sentido de posse, pois acrescenta:

4 Doravante todas as citações da Retórica serão extraídas de: ARISTÓTELES. Retórica. Tradução de Manuel Alexandre Júnior. 3. ed. Lisboa: Imprensa Nacional/Casa da Moeda, 2006. 
Ora, se os bens honoríficos provocam emulação, necessariamente também as virtudes semelhantes a provocarão e tudo quanto é útil e benéfico aos outros (porque as pessoas têm em consideração os benfeitores e as pessoas de bem). E o mesmo acontece com todas as coisas boas que podemos usufruir com os que estão próximos de nós, por exemplo, a riqueza e a beleza, mais até que a saúde (Ret.1388b).

Aristóteles não trata da emulação em sua Poética, mas há uma similaridade com a questão da imitação (mimesis) como podemos observar:

(...) e, estando nós em posse, conforme à natureza do imitar, da melodia e do ritmo (pois é evidente que os metros fazem parte do ritmo), desde o início os mais naturalmente dotados para tais coisas, progredindo aos poucos, engendraram a composição a partir das improvisações. Mas a composição desmembrou-se segundo os caracteres apropriados: os mais solenes imitavam as ações nobres e de pessoas desse tipo, enquanto os menos exigentes as das pessoas ruins, inicialmente compondo injúrias, assim como os outros hinos e encômios. (Poet. IV, 1448b20-7).

Ao incluir a beleza em sua lista de bens emuláveis, Aristóteles dá um importante passo na direção do que será, bem mais tarde, a Estética, e sua influência será percebida em autores posteriores, como o já visto anteriormente, Dionísio de Halicarnasso que em sua obra Sobre a Imitação afirma:

A imitação é a atividade que guarda o modelo por meio das regras, mas, como dizem os sucessores, discurso ou ação que contem uma semelhança bem sucedida com o modelo. Emulação é a atividade de uma alma movida para admiração pelo que ela acha que é belo (apud VELOSO, 2004, p.241).

Desta forma podemos imaginar que, sendo a beleza um bem emulável, assim também poderemos tratar todas as manifestações artísticas, incluindo a música.

Bach ao realizar suas paródias segue o princípio emulativo, visando sempre, ao adaptar obras previamente compostas, a qualidade, ou como disse Aristóteles, o bem. 0 modelo musical a ser parodiado é um paradigma, uma amostra com base na qual escolhemos certa coisa. Se para Aristóteles, 
pelo paradigma se aprende, como dito desde o início na Poética, para Bach, a paródia é um paradigma onde igualmente a mensagem religiosa nela contida está assegurada de ser transmitida.

Podemos notar uma analogia entre a teoria aristotélica da emulação e as paródias realizadas por Bach, uma vez que Bach não realizava uma simples cópia de uma obra anterior, mas, ao contrário, em sua reutilização, sempre procurava a adequação e a melhoria do discurso. Como vimos, tais preceptivas de imitação/paródia do discurso com base na adequação, unidade, beleza e preceitos morais também foram encontrados na teoria de diversos retóricos posteriores a Aristóteles.

A paródia bachiana é uma imitação de caráter emulativo, pois não se trata de mera repetição de trechos musicais em alturas diferentes, como previsto nos tratados de 202 composição, mas de uma escolha criteriosa, carregada de valores morais e que leva em conta tanto os preceitos da composição, quanto os da retórica musical. Esta atitude de Bach mantém um completo alinhamento com as preceptivas de Aristóteles encontradas na Poética e na Retórica, que perpassaram tantos autores e compositores ao longo da história, como demonstrado.

Além da emulação, duas outras ferramentas imitativas foram utilizadas na prática musical: a contrafactum e a paródia. Estes são termos que, por princípio, estavam ligados às atividades literárias, sendo apenas posteriormente indicativos de atividades musicais. Ambos, ao serem utilizados para substituírem um texto por outro, mantendo-se a antiga melodia, assumem claramente a função de tropo retórico musical, ferramenta esta que se fará presente de diversas formas nas composições de Bach.

No que concerne à atividade musical, por definição a paródia e a contrafactum são o resultado de uma melodia, ou toda composição, que foi tomada e reutilizada, alterada ou não. Tanto a paródia quanto a contrafactum são atividades que, mesmo no âmbito musical, geralmente estarão relacionadas com a utilização de algum texto. Segundo Robert Falk (1979, 
p.1), a distinção entre paródia e contrafactum é uma questão apenas de nomenclatura. De acordo com ele (in SADIE, 2001, v.6, p.367), antes de 1450, o termo contrafactum era mais comumente empregado para indicar a prática de compor novos poemas para melodias antigas, particularmente no repertório monofônico secular dos séculos XII e XIII. No repertório sacro de cantochão ele é igualmente encontrado, quando, por exemplo, os textos de novas festividades eram rotineiramente adaptados para antigas melodias. Falk afirma ainda que muitas melodias de Sequentia e hinos também tiveram os textos reescritos numerosas vezes. A palavra contrafactum (ou contrafacere) foi utilizada durante a Idade Média com o significado de imitação em geral, no entanto sempre com uma conotação negativa de contrafeito, ou seja, algo falso ou dissimulado. Falk indica ainda que o uso mais antigo do termo contrafactum, no sentido moderno de imitação musical, data do século XV aparecendo no manuscrito alemão de Pfulligen e restringia-se a adaptações de texto de melodias seculares para uso sacro. Nos séculos XV e XVI a contrafactum frequentemente envolvia a substituição de texto sacro para secular, ocorrendo o inverso apenas raramente.

Durante o período da Reforma protestante, a contrafactum, agindo como tropo, foi uma categoria particularmente importante na adaptação de canções profanas para corais luteranos. Nestas obras a melodia se conservava mas o texto era substituído por uma letra inteiramente nova, ou pelo menos alterado de maneira a conferir-lhe um sentido religioso (GROUT, 2001, p. 278).

A contrafactum também aparece no repertório monofônico secular. Em alguns casos, uma nova canção empresta tanto a melodia como partes de um texto já existente em uma atitude de tributo, ou talvez, competição. Alguns Minnelieder alemães são contrafacta ou adaptações de canções de troubadour ou trouvère e, com certa frequência, melodias seculares eram dispostas em textos sacros latinos (FALK in SADIE, 2001, v.4, p.9).

No campo musical, a paródia é um termo usado para remeter a uma técnica de composição envolvendo o uso de 
material pré-existente primeiramente associada ao século XVI (SADIE, 2001, v19, p. 145). Apesar da palavra grega paródia $(\pi \alpha \rho \omega \delta 1 \alpha)$ aparecer já no início do século IV a.C., é apenas na metade do século XVI que se iniciam as discussões sobre sua utilização em atividade musical. Embora a técnica de paródia tenha sido importante, particularmente na composição das missas durante o século XVI, o termo parodia em si não foi utilizado até 1587 quando aparece no título da página de rosto da Missa de Jakob Paix com a seguinte inscrição em latim "Missa Parodia mottetae Domine da nobis auxilium Thomae Crequillonis". Até então, a denominação usual pela qual o empréstimo de material era conhecido era "Missa super (...)" ou "Missa ad imitationem (...)" seguida pelo título do trabalho na qual a missa estava baseada (FALCK, 1979, p.4). A preferência de J. Paix pela utilização de um termo grego foi resultado da grande influência humanística alemã.

No século XVI, o procedimento de composição de missas polifônicas apresenta a utilização generalizada da paródia. Ainda que já fosse utilizada no século precedente, em geral tendo canções seculares como ponto de partida, a paródia permanecia tímida e não se distinguia claramente da utilização de monodias preexistentes. No século XVI, ao contrário, observa-se o empenho em explorar os modelos escolhidos tanto em sua estrutura polifônica quanto em seus temas melódicos: não se hesita em citar literalmente certas passagens, para melhor desenvolvê-las em novas elaborações contrapontísticas. Este processo de cópia e paródia foi muito utilizado no período de Bach. Bach normalmente realizava as paródias entre obras sacras e seculares da seguinte maneira: música de Paixão era reutilizada como música de funeral; música de funeral era adaptada para se tornar música de Paixão; música composta em honra ao nascimento do filho de um monarca era reutilizada mais tarde para celebrar o nascimento do Filho de Deus (BUTT, 1997a, p.90). Desta forma, podemos observar que na transposição entre o texto original da melodia para um texto novo, o compositor sempre guardava o decoro da matéria e fazia uma analogia temática. Werner Neumann, que estudou particularmente a questão da paródia em Bach, distingue cinco modelos de operação (apud BASSO, 
1985, Vol. II, p.270): reutilização de uma cantata sacra por uma outra cantata sacra; reutilização de uma cantata profana por uma cantata sacra; reutilização de uma cantata profana por uma cantata profana; reutilização de uma obra instrumental por uma obra vocal; reutilização de uma obra vocal por uma obra instrumental.

Como se observa, Bach jamais transforma cantatas sacras em profanas, demonstrando assim uma particular sensibilidade aos elementos espirituais de origem, que não podem ser "rebaixados" ao nível de obras profanas; estas, porém, podem ter seus elementos "elevados" ao nível de uma cantata sacra. Através deste mecanismo fica evidente a importância dada por ele à adequação ao gênero do discurso, pois um discurso de gênero baixo poderia ou ser transformado em outro do mesmo gênero ou ser elevado, porém o mesmo não ocorreria com um discurso elevado, que poderia no máximo ser transformado em outro do mesmo gênero, mas nunca ser rebaixado.

As composições de Bach não tinham a intenção primária de "deleite" de um público de concerto, mas sim a "edificação" de uma congregação de igreja. As cantatas foram concebidas não como peças de concerto, mas sim como sermão musical. Autores como Spitta comentam que Bach, mesmo ao compor obras seculares, escrevia de maneira sacra (BUTT, 1997a, p.90).

O mecanismo da paródia será amplamente utilizado por Bach em várias obras, porém pode ser observado com maior ênfase no Oratório de Natal, nas Missas Breves e, sobretudo, na Missa em Si menor.

\section{Paródias na Missa em Si menor, BWV 232}

Frequentemente tive a oportunidade de comparar os textos originais e subsequentes de seus trabalhos e confesso sempre me surpreender e me emocionar ao observar a sua 
dedicação para realizar melhorias, (...) tornando o bom, melhor e o melhor, perfeito 5 (FORKEL, 1802, p.62).

Assim inicia o Capítulo X da biografia de Bach escrita por Johann Nikolaus Forkel, seu primeiro biógrafo. Embora no trecho acima Forkel esteja se referindo às parodias de uma maneira geral, é na Missa em Si menor que podemos encontrar o apogeu da técnica do processo.

A obra é composta por vinte e sete movimentos, sendo vários parodiados de antigas composições, em geral, movimentos de cantatas sacras e profanas que fossem semelhantes quanto ao conteúdo. Entretanto, há ainda muita controvérsia sobre as fontes utilizadas por Bach na composição da Missa. Em consequência de novas pesquisas e descobertas sobre a obra de Bach, houve, através do tempo, um significante aumento do número do que se pode considerar movimentos parodiados na Missa. Em nosso trabalho, após a compilação de dados que consta nos principais autores ${ }^{6}$, o número de movimentos parodiados seria, aparentemente, dezoito, porém se considerarmos as pesquisas do musicólogo alemão Klaus Häfner (1987, p.530), que em Aspekte des Parodieverfahrens bei Johann Sebastian Bach realiza um estudo minucioso das paródias na obra de Bach, este número passaria para vinte e quatro, ou seja, quase a totalidade da obra. Desta forma, no que se refere ao número de movimentos parodiados, a Missa em Si menor se aproximaria muito das Missas Breves.

\footnotetext{
${ }^{5}$ Ich habe Gelegenheit gehabt, viele Abschriften seiner Hauptwerke aus verschiedenen Jahren mit einander zu vergleichen, und ich muß gestehen, daß ich mich oft über die Mittel gewundert und gefreut habe, deren er sich bediente, um nach und nach das Fehlerhafte gut, das Gute besser und das Bessere zum Allerbesten zu machen.

6 Dados coletados a partir das informações retiradas dos autores: BUTT (1991), CARRELL (1967), DÜRR (2000), HÄFNER (1987), KÜSTER (1999), NEUMANN (1984), RILLING (1986), SCHWEITZER (1966), SMEND (2006), SPITTA (1951), STAUFFER (2003), TERRY (1931), WOLFF (2000b e 2009).
} 
No tocante ao número de paródias na Missa, Klaus Häfner (1987, p.240), considera contraditório às leis da probabilidade pensar que apenas um quarto dos movimentos dela seja realizado com a técnica da paródia. Acredita ele que, em vez de fazer uma criação nova, deve-se supor que o compositor tenha utilizado a mesma técnica em todo o processo. Segundo o autor, o resultado destas reflexões se confirma através dos manuscritos autógrafos, que apresentam partes tão limpas e isentas de correções que podem ser, assim como também Spitta e Schering as consideravam, originais que foram transportados. Häfner relata que von Dadelsen, outro importante musicólogo alemão, caracterizava a partitura da Missa em Si menor como um manuscrito que oferece quase que a imagem de uma escrita original.

A Tabela 1 indica a estrutura da Missa, com todos os vinte e sete movimentos, bem como os movimentos parodiados com seus respectivos originais.

\begin{tabular}{|l|l|}
\hline Partes/ano & Paródia de BWV/ ano \\
\hline
\end{tabular}

\section{Missa - Kyrie (1733)}

\begin{tabular}{|l|l|}
\hline $1^{\circ}$. Kyrie (coro) & 198 ou D.Messe de Lutero \\
\hline $2^{\circ}$. Christe (dueto) & $\begin{array}{l}\text { manuscrito limpo sugere paródia } \\
(\text { BWV Anh.9/8) }\end{array}$ \\
\hline $3^{\circ}$. Kyrie (coro) & $\begin{array}{l}\text { manuscrito limpo sugere paródia } \\
(\text { BWV 244a/8 }=14)\end{array}$ \\
\hline
\end{tabular}

\section{$\underline{\text { Gloria }}$}

\begin{tabular}{|l|l|}
\hline $4^{\circ}$. Gloria (coro) & $\begin{array}{l}191 / 1 \text { ou Derivado de um concerto } \\
\text { instrumental(?)/ Similaridades } \\
201,206,214,215(1718-23)\end{array}$ \\
\hline $5^{\circ}$. Et in terra pax (coro) & \\
\hline $6^{\circ}$. Laudamus (ária) & $($ BWV Anh.9/6) \\
\hline $7^{\circ}$ Gratias (coro) & $29 / 2(1731)$ \\
\hline $8^{\circ}$. Domine Deus (dueto) & $191 / 2,193 a / 5(1727)$ \\
\hline $9^{\circ}$. Qui tollis (coro) & $46 / 1$ (Seção A) $(1723)$ \\
\hline $10^{\circ}$. Qui Sedes (ária) & manuscrito limpo sugere paródia \\
\hline
\end{tabular}




\begin{tabular}{|l|l|}
\hline & (BWV Anh. 9/12) \\
\hline $11^{\circ}$. Quoniam (ária) & (BWV Anh. 9/10) \\
\hline $\begin{array}{l}12^{\circ} . \text { Cum Sancto spiritu } \\
\text { (coro) }\end{array}$ & $\begin{array}{l}\text { 191/3/ou concerto instrumental } \\
\text { perdido }\end{array}$ \\
\hline
\end{tabular}

\section{Symbolum Nicenum (Credo) (c.1747-49)}

\begin{tabular}{|l|l|}
\hline $13^{\circ}$. Credo (coro) parte I & $\begin{array}{l}\text { Baseado em Cantochão latino e/ou } \\
\text { retrabalhado à partir do Magnificat de } \\
\text { Caldara Credo Niceno de Bassani e/ou } \\
\text { Coro de abertura de 205 }\end{array}$ \\
\hline $\begin{array}{l}14^{\circ} \text {. Credo Patrem (coro) } \\
\text { parte II }\end{array}$ & $\begin{array}{l}\text { Paródia Gott, wie dein Name, so ist } \\
\text { auch dein Ruhm 171/1 (1729?); Coro } \\
\text { Credo in unum Deum em Sol (c.1747- } \\
1748)\end{array}$ \\
\hline $\begin{array}{l}15^{\circ} . \text { Et in unum Dominum } \\
(\text { dueto) }\end{array}$ & $\begin{array}{l}\text { Dueto perdido, considerado 213/11 } \\
(1733)\end{array}$ \\
\hline $16^{\circ}$. Et incarnatus (coro) & $\begin{array}{l}12 / 2 \text { (Seção A) (1714)/ Baixo do Coro } \\
\text { I, derivado de 78 }\end{array}$ \\
\hline $17^{\circ}$. Crucifixus (coro) & $\begin{array}{l}\text { Anh. 9/1 (Seção A) (1727)/ou obra } \\
\text { instrumental }\end{array}$ \\
\hline $18^{\circ}$. Et resurrexit (coro) & (BWV Anh. 4/2) \\
\hline $19^{\circ}$. Et in Spiritum (ária) & $\begin{array}{l}2^{\text {a }} \text { Parte 120/2 (1728-29)120/2 - } \\
120 a / 1\end{array}$ \\
\hline $20^{\circ}$. Confiteor (coro) & \\
\hline $21^{\circ}$. Et expecto (coro) & \\
\hline
\end{tabular}

\section{Sanctus (1724)}

\begin{tabular}{|l|l}
\hline $22^{\circ}$. Sanctus (coro) & Sanctus, 232/III (1724)
\end{tabular}

\section{Osanna, Benedictus, Agnus Dei, Dona nobis pacem}

\begin{tabular}{|l|l|}
\hline $23^{\circ}$. Osanna (coro) & $\begin{array}{l}11 / 1 \text { (Seção A) (1732) (=Anh. 11), } \\
\text { ou/ Depois 215/1 (1734) }\end{array}$ \\
\hline $24^{\circ}$. Benedictus (ária) & Cantata profana (?) (BWV Anh 13/5) \\
\hline $25^{\circ}$. Osanna (da capo)(coro) & \\
\hline $26^{\circ}$. Agnus Dei (ária) & $\begin{array}{l}\text { Anh. 196/3 (1725); ou "Oratório } \\
\text { Ascensão" 11/4 (1735?) }\end{array}$ \\
\hline
\end{tabular}




\begin{tabular}{|l|l|}
$27^{\circ}$. Dona nobis pacem (coro) & $\begin{array}{l}\text { 232/7 (1733); ou 29/2 (=n.7) (1731); } \\
\text { ou uma fonte comum tardia }\end{array}$ \\
\hline
\end{tabular}

Tabela 1: Estrutura da Missa em Si menor ${ }^{7}$

O hábito, e talvez a necessidade, que Bach tinha de parodiar e retrabalhar a música já composta constituía uma adaptação natural à pressão dos seus deveres. Desta forma lhe era possível também tornar a ouvir, sob uma forma diferente, trechos musicais a que dedicara grande dose de reflexão e energia criadora. Porém, não é neste contexto específico que as paródias da Missa em Si menor devem ser vistas. Elas não são frutos de pressão ou hábito composicional, não sendo mecanicamente feitas; ao contrário, devido à laboriosa adaptação do novo texto, que deveria conter o mesmo sentido teológico que o anterior, a uma a música pré-concebida, faz com que cada um dos movimentos parodiados mostre um grau de perfeição superior ao de seu modelo. Lembrando ainda que esta readaptação era feita através da utilização do tropo como recurso poético-musical. Assim, este fato nos faz indagar sobre a possibilidade de Bach ter tido o conhecimento teórico do pensamento aristotélico da mimese e especialmente da emulação e, na utilização das paródias, ter sido influenciado por elas.

Os procedimentos de composição das paródias da Missa em Si menor são diferentes em relação às demais paródias. Era comum Bach, ao revisar suas obras, expandir o material pré-existente, embelezando as linhas, modificando texturas, adicionando compassos e compondo novas seções. $\mathrm{Na}$ Missa em Si menor, no entanto, ele segue o caminho inverso, reduzindo as seções e diminuindo compassos para adaptá-los ao texto latino, como ocorre, por exemplo, nos movimentos do Osanna e Agnus Dei (trinta e três compassos menor que o original), ou no Qui tollis (quinze compassos menor).

A Missa em $\mathrm{Si}$ menor pode ser considerada um "resumo" da obra de Bach, uma espécie de catálogo de obras, pois nela encontram-se cantatas de seu período em Weimar

7 Os originais apresentados entre parêntesis, referem-se aos estudos de Klaus Häfner (1987, p. 530). 
(BWV 12, parodiada no Crucifixus), cantatas dos seus cinco Ciclos do período de Leipzig (BWV 46, parodiada no Qui tollis ou a BWV 171, parodiada no Patrem Omnipotentem) e obras escritas para o Collegium Musicum de Leipzig no período de 1730 (BWV Anh.11, parodiado no Osanna). Além disso encontra-se música feita para a igreja (BWV 46, 171), para cerimônias burocráticas (BWV 29,120) e eventos cerimoniais (BWV Anh.9, Anh.11).

George Stauffer (2003, p.263) acredita que a síntese de estilos composicionais contribui para uma universalidade da Missa em Si menor. Diz ele que a obra é uma verdadeira réunion des goûts (usando o termo de Couperin), uma reunião de gostos, onde existe desde a justaposição de estilos, como por exemplo no Credo e no Confiteor, em que são combinados um coro renascentista com uma linha, tipicamente barroca, de baixo contínuo, além do estilo antigo, moderno, italiano, francês e alemão, estruturas vocais e instrumentais, que são 210 amalgamados em uma obra única e contínua.

Bach ao realizar suas paródias segue o princípio emulativo, visando sempre, ao adaptar obras previamente compostas, a qualidade, ou como disse Aristóteles, o bem. 0 modelo musical a ser parodiado é um paradigma, uma amostra com base na qual escolhemos certa coisa. Se para Aristóteles, pelo paradigma se aprende, como dito desde o início na Poética, para Bach, a paródia é um paradigma onde igualmente a mensagem religiosa nela contida está assegurada de ser transmitida.

Podemos notar uma analogia entre a teoria aristotélica da emulação e as paródias realizadas por Bach, uma vez que Bach não realizava uma simples cópia de uma obra anterior, mas, ao contrário, em sua reutilização, sempre procurava a adequação e a melhoria do discurso. Assim, a paródia bachiana pode entendida como uma imitação de caráter emulativo, pois não se trata de mera repetição de trechos musicais em alturas diferentes, como previsto nos tratados de composição, mas de uma escolha criteriosa, carregada de valores morais e que leva em conta tanto os preceitos da composição, quanto os da retórica musical. Esta atitude de Bach mantém um completo alinhamento com as preceptivas de Aristóteles encontradas na Poética e na Retórica, que perpassaram tantos autores e 
compositores ao longo da história, como demonstrado. Sabe-se que Bach estudava retórica e o quanto conhecia de Aristóteles não se encontra documentado. No entanto, a proximidade de Bach com o teórico Johann Gottsched, sugere um conhecimento de ideias do estagirita pelo compositor, pois é inegável a semelhança de conduta de ambos no valor dado à imitação, no seu caráter específico de emulação e principalmente no procedimento moral ao empregá-las.

Bach reúne na Missa, a retórica com a liturgia, a literatura com a música. Mas, sobretudo, a mais importante fusão na Missa é o encontro espiritual entre os mundos católico e luterano, proporcionando assim, uma maneira dupla de revelação dos mistérios e glorificação, realizando sua Missa em Si menor somente para a glória de Deus.

\section{Referências bibliográficas}

ARISTÓTELES. Poética. Lisboa: Imprensa Nacional - Casa da Moeda, 2003.

Retórica. Lisboa: Imprensa Nacional - Casa da Moeda, 1998.

BASSO, A. Jean Sébastien Bach Vol. II. Paris: Librairie Arthème Fayard, 1985.

BROWN, H.M. Emulation, Competition and Homage: Imitation and Theories of Imitation in the Renaissance. Journal of the American Musicological Society, vol. 35, No.1, pp.1-48, 1982. Disponível em: http://links.jstor.org/sici?sici=0003-

0139\%28198221\%2935\%3A1\%3C1\%3AECAHIA\%3E2.0.CO\%3B2-1

Acesso em: 28.09.2007.

BUTT, J. (Ed.). The Cambridge Companion to Bach. Cambridge: Cambridge University Press, 1997a.

BUTT, J.; RUSHTON, J. (Eds). Bach: Mass in B minor. Cambridge: Cambridge University Press, 1991.

DÜRR, A. Johann Sebastian Bach - Die Kantaten. München: BärenreiterVerlag, 2000.

FALCK, R. Parody and Contrafactum: A terminological Classification. The Musical Quarterly, Vol. 65, No. 1, January, 1979, pp.1-21. Disponível em: http://links.jstor.org/sici?sici=0027- 
4631\%28197901\%2965\%3A1\%3C1\%3APACATC\%3E2.0CO\%3B2-M Acesso em 28.09.2007

GROUT, D.J.; PALISCA, C.V. História da Musical Ocidental. Lisboa: Gradiva, 2001.

HANSEN, J. A. Imitação na representação seiscentista. (texto não publicado)

MATTHESON, J. Der vollkommene Capellmeister. Kassel: Bärenreiter , 1999.

NEUMANN, W. Handbuch der Kantaten Johann Sebastian Bachs. WIESBADEN: BREITKOPF \& HÄRTEL, 1984.

SADIE, S. (Ed). The New Grove Dictionary of Music and Musicians. Macmillan Publishers Limited, USA, 2001.

SCHWEITZER, A. J. S. Bach Vol. I. New York: Dover Publications, 1966.

SLOANE, T. O. Encyclopedia of Rhetoric. New York: Oxford University Press, 2001.

212 SMEND, F. Messe in h-Moll - Urtext der Neuen Bach-Ausgabe. Kassel: Bärenreiter-Verlag, 2006.

SPITTA, P. Johann Sebastian Bach, Vol II. New York: Dover Publication, 1951.

STAUFFER, G. Bach - The Mass in B Minor - The Great Catholic Mass. Yale: Yale University Press, 2003.

TESAURO, E. Il Cannocchiale Aristotelico O Sia Idea Dell'Arguta Et Ingeniosa Elocutione Que Serve À Tutta L'Arte Oratoria, Lapidaria, Et Simbolica Esaminata Co'Principij Del Divino Aristotele (Torino, 1654) (fac-simile). Savigliano: Editrice Artistica Piemontese, 2000.

TERRY, C. S. Bach's B minor Mass. London: Oxford University Press, 1931.

VELOSO, C. W. Aristóteles Mimético. São Paulo: Discurso Editorial, 2004.

WEINBROT, H. "An ambition to excell": the aesthetics of emulation in the seventeenth and eighteenth centuries. The Huntington Library Quaterly, vol. 48, no. 2, (spring, 1985), pp.121-139. Disponível em: http://www.jstor.org/stable/3817539 Acesso em : 28.09.2007.

WOLFF, C. Johann Sebastian Bach - The Learned Musician. New York: W.W. Norton \& Company, 2000b. 
WOLFF, C.; KOOPMAN, T. Die Welt der Bach Kantaten Bd. 3. Stuttgart: Metzler Bärenreiter, 1999. 